\title{
Polymorphism of SLC14A1 encoding human erythrocytic Kidd antigens in the Chinese population
}

\author{
Haochun Chang ${ }^{1,2,3}$, Hsin-Wan Chen ${ }^{1}$, Chen Cao ${ }^{2,3}$, Xiaoiie Zhu ${ }^{2,3}$, Zhenzhen Zhou ${ }^{2}$, Yu-Shiang Lin ${ }^{1,2,3^{*}}$ \\ ${ }^{1}$ Department of Clinical Medicine, School of Basic Medical Sciences, Peking University Health Science Center, Beijing, 100191, China; \\ ${ }^{2}$ Nobel Prize Medicine Research Institute, Jiangsu ZhongJi WanTai Biological Pharmacetiual Co., Ltd., Jiangyin, Jiangsu, 214400, China; \\ ${ }^{3}$ The United Reference Laboratory for Blood Group Gene Detection, Jiangsu Libo Medicine Biotechnology Co., Ltd., Jiangyin, Jiangsu, \\ 214400, China.
}

\begin{abstract}
The SLC14Al gene, which encodes important Kidd blood group antigens, has not been systematically analyzed at the molecular level in Chinese individuals. In this study, SLC14Al genetic polymorphism was examined in Chinese individuals with $\mathrm{Jk}(\mathrm{a}+\mathrm{b}-), \mathrm{Jk}(\mathrm{a}+\mathrm{b}+)$, and $\mathrm{Jk}(\mathrm{a}-\mathrm{b}+)$ expression. The Kidd phenotype was determined for 146 specimens using monoclonal anti-Jk ${ }^{\mathrm{a}}$ and $-\mathrm{Jk}^{\mathrm{b}}$ antibodies. From these, 87 specimens were $\mathrm{Jk}(\mathrm{a}-\mathrm{b}+), 21$ were $\mathrm{Jk}(\mathrm{a}+\mathrm{b}-)$, and 38 were $\mathrm{Jk}(\mathrm{a}+\mathrm{b}+)$. According to the Kidd phenotype results, 20 specimens were randomly selected from each group, i.e., $\mathrm{Jk}(\mathrm{a}-\mathrm{b}+), \mathrm{Jk}(\mathrm{a}+\mathrm{b}-)$, and $\mathrm{Jk}(\mathrm{a}+\mathrm{b}+)$, for the molecular analyses of exons 3 to 11 of the SLC14A1 gene. Novel alleles were detected in the SLC14A1 gene, including IVS3-106A, IVS3-99A, exon3 130G, IVS4-299G, IVS4-293G, IVS4+211C, IVS4 +230C, exon6 499A, exon6 588A, IVS7-68T, IVS9+244G, and IVS10-153T, indicating that the locus harbored significant polymorphism. We also showed that IVS4-299, IVS7-68, and IVS10-153 were novel SNPs absolutely associated with exon 8 nt.838. The minor allele frequencies were all greater than $10 \%$ and all SNPs in the Chinese population showed Vel antigen expression on RBC membranes. We identified 12 SNPs in the SLC14A1 gene in the Chinese population, IVS3-106A, IVS399A, exon3 130G, IVS4-299G, IVS4-293G, IVS4+211C, IVS4+230C, exon6 499A, exon6 588A, IVS7-68T, IVS9+244G, and IVS10-153T. Our results also indicated that three novel SNPs produced $\mathrm{Jk}^{\mathrm{a}}$ and $\mathrm{Jk}^{\mathrm{b}}$ antigens in Chinese individuals.
\end{abstract}

Keywords: polymorphism, SLC14A1, human erythrocytic antigens, Kidd

\section{INTRODUCTION}

The Kidd glycoprotein is a transmembrane protein that functions as a urea transporter. $\mathrm{Jk}(\mathrm{a}-\mathrm{b}-)$ is a rare null phenotype lacking the high-incidence Jk3 antigen $\left(\mathrm{Jk}_{\text {null }}\right)$. The $S L C 14 A 1$ locus is located on chromosome 18 at $18 \mathrm{q} 11-\mathrm{q} 12$, spans approximately $30 \mathrm{~kb}$ con-

*Correspondence to: Yu-Shiang Lin, Nobel Prize Medicine Research Institute, Jiangsu ZhongJi WanTai Biological Pharmacetiual Co., Ltd., Jiangyin, Jiangsu, 214400, China. TEL: 0086-510-81695199. E-mail: 1448639963@qq.com.

The authors declared no conflict of interests. taining 11 exons, and constitutes the Kidd (Jk) blood group system (ISBT009) ${ }^{[1]}$.

$\mathrm{Jk}(\mathrm{a}-\mathrm{b}-)$ red blood cells are easily identified by their failure to lyse in $2 \mathrm{~mol} / \mathrm{L}$ urea, distinguishing them from other Kidd phenotypes with normal urea transporter function ${ }^{[2]}$. Natural or transfusion-related immune anti-Jk3 has been identified in people with $\mathrm{Jk}(\mathrm{a}-\mathrm{b}-)$ and anti-Jk3 is responsible for severe immediate and delayed hemolytic transfusion reactions and newborn hemolytic disease ${ }^{[3]}$. A rare blood bank from Shanghai and Taipei reported that $\mathrm{Jk}_{\text {null }}$ had the highest incidence in the Chinese population ${ }^{[4]}$.

The most common molecular variant causing $\mathrm{Jk}_{\text {null }}$ is the IVS5-1 mutation, which is an RNA splice site 
error. However, genetic polymorphisms in SLCI4AI have not been investigated in the Chinese population. Homozygous IVS3-78 A $>$ G mutations have been reported in $\mathrm{Jk}_{\text {null }}$ individuals and individuals expressing normal $\mathrm{Jk}(\mathrm{a}-\mathrm{b}+)^{[5-11]}$. We previously performed a pedigree analysis of anti-Jk3-induced newborn hemolytic disease and found that genetic polymorphisms in SLC14A may explain the controversial results in the Chinese population, while discussing molecular variation in $\mathrm{Jk}_{\text {null }}$ individuals $^{[12]}$. Therefore, we examined SLC14AI polymorphism in the Chinese population and expected the results to offer insight into the molecular basis of $\mathrm{Jk}_{\text {null }}$ individuals.

The aim of our study was to characterize the sequences of normal serological Kidd antigens in Chinese individuals. Notably, this is the first study to investigate SLC14AI gene polymorphism in an Asian population.

\section{MATERIAL AND METHODS}

\section{Data collection and DNA extraction}

EDTA peripheral venous blood specimens were examined by the direct and indirect Coombs tests, and serological Kidd phenotyping was performed by 2 $\mathrm{mol} / \mathrm{L}$ urea hemolytic tests and monoclonal antibody against $\mathrm{Jk}^{\mathrm{a}}$ and $\mathrm{Jk}^{\mathrm{b}}$ (Pelikloon anti-Jk $\mathrm{K}^{\mathrm{a}}$ [IgM] monoclonal and Pelikloon anti-Jk ${ }^{\mathrm{b}}[\operatorname{IgM}]$ monoclonal, Sanquin $\mathrm{GmbH}$, Netherlands). The exclusion criteria were positive direct or indirect Coombs tests or positive in the $2 \mathrm{~mol} / \mathrm{L}$ urea hemolytic test.

Peripheral EDTA-treated anti-coagulated blood was stored at $4{ }^{\circ} \mathrm{C}$. Serological tests and DNA extraction were performed within 12 hours of blood acquisition. DNA was purified from the buffy coat samples using micromagnetic technology with a commercial kit (Magnetic Bead; Texas Biotechnology Co., Ltd., Xiamen, China) and an automatic instrument (EZ Bead32, Texas Biotechnology Co., Ltd., Xiamen, China. All DNA samples were stored at $-80^{\circ} \mathrm{C}$ until required for molecular analysis.

\section{Genotyping and molecular analysis}

Kidd blood group genotyping was performed by polymerase chain reaction (PCR) with sequencespecific primers using a commercial kit (Human Rare Erythrocytic Antigen Genotype; Jiangsu ZhongJi WanTai Biological Pharmaceutical Co., Ltd., Jiangsu, China). Sanger sequencing of Kidd exons 3 to 11 was performed using a commercial Kidd gene sequencing kit (Kidd E3-11 Sequence; Jiangsu ZhongJi WanTai Biological Pharmaceutical Co., Ltd, Jiangsu, China).
Sequencing of PCR-purified products was performed by Sangon Biotech (Beijing, China) and the results were analyzed using sequence analysis software (Geneious R9; Auckland, New Zealand). The SLC14A1 allele sequence (GenBank No. NM 015865.1) template was used as a reference for analyses and to mark mutations.

Genetic linkage in the SLC14AI allele could not be identified. The data were grouped according to $\mathrm{Jk}(\mathrm{a}+\mathrm{b}-), \mathrm{Jk}(\mathrm{a}-\mathrm{b}+), \mathrm{Jk}(\mathrm{a}+\mathrm{b}+)$, and $\mathrm{Jk}(\mathrm{a}-\mathrm{b}-)$ phenotypes based on serological results and genetic linkage with nt.838 in exon 8 from SLC14A1, which is a single nucleotide polymorphism (SNP) for the $\mathrm{Jk}^{\mathrm{a}}$ antigen (nt.838G) and $\mathrm{Jk}^{\mathrm{b}}$ antigen (nt.838A) and was examined.

\section{RESULTS}

\section{Baseline}

All 146 random specimens obtained from employee health examinations were negative in both $2 \mathrm{~mol} / \mathrm{L}$ urea hemolytic testing and antibody screening. Of the 146 specimens were examined to determine the Kidd phenotype using monoclonal anti- $\mathrm{Jk}^{\mathrm{a}}$ and $-\mathrm{Jk}^{\mathrm{b}}$ antibodies; 87 specimens were $\mathrm{Jk}(\mathrm{a}-\mathrm{b}+), 21$ were $\mathrm{Jk}(\mathrm{a}+\mathrm{b}-)$, and 38 were $\mathrm{Jk}(\mathrm{a}+\mathrm{b}+)$. According to the Kidd phenotype results, we random selected 20 specimens from each group, i.e., $\mathrm{Jk}(\mathrm{a}-\mathrm{b}+), \mathrm{Jk}(\mathrm{a}+\mathrm{b}-)$, and $\mathrm{Jk}(\mathrm{a}+\mathrm{b}-)$ for molecular analyses of exons 3 to 11 of the SLC14AI gene.

\section{Molecular analysis of exons 3 and 4 of SLC14A1 gene}

Nine single nucleotide variants were found at exons 3 and 4 of the SLC14AI gene, including IVS3106A, IVS3-99A, exon3 130G, IVS4-299G, IVS4$293 \mathrm{G}$, exon4 191G, IVS4+177T, IVS4+211C, and IVS4+230C(Table 1). The seven single nucleotide variants IVS3-106A, IVS3-99A, exon3 130G, IVS4-299G, IVS4-293G, IVS4+211C, and IVS4+230C were polymorphic and did not influence $\mathrm{Jk}^{\mathrm{a}}$ or $\mathrm{Jk}^{\mathrm{b}}$ antigen expression because all specimens in our study exhibited normal expression of Kidd antigens. The IVS4-299G SNP was absolutely related to nt.838; homozygous IVS4-299CC was associated with homozygous nt.838GG, which expresses the Jk(a+b-) antigen; heterozygous IVS4-299GC was associated with heterozygous nt.838GA, which expresses $\mathrm{Jk}(\mathrm{a}+\mathrm{b}+)$ antigen; and homozygous IVS4299GG was associated with homozygous nt.838AA, which expresses $\mathrm{Jk}(\mathrm{a}-\mathrm{b}+)$.

\section{Molecular analysis of exons 5 and 6 of $S L C 14 A 1$ gene}

Five single nucleotide variants were found at exons 5 and 6 of the SLC14AI gene, including IVS5-1G, 
Table 1 The single nucleotide variants between exon 3 and 4 of SLC14A1 gene

\begin{tabular}{|c|c|c|c|c|}
\hline Alleles & $\mathrm{Jk}(\mathrm{a}+\mathrm{b}-)$ & $\mathrm{Jk}(\mathrm{a}+\mathrm{b}+)$ & $\mathrm{Jk}(\mathrm{a}-\mathrm{b}+)$ & Total \\
\hline \multicolumn{5}{|l|}{ Exon8 838G } \\
\hline GG & $20(100)$ & $0(0)$ & $0(0)$ & $20(33)$ \\
\hline GA & $0(0)$ & $20(100)$ & $0(0)$ & $20(33)$ \\
\hline AA & $0(0)$ & $0(0)$ & $20(100)$ & $20(33)$ \\
\hline \multicolumn{5}{|l|}{ IVS3-106A } \\
\hline AA & $20(100)$ & $0(0)$ & $11(55)$ & $31(52)$ \\
\hline AG & $0(0)$ & $9(45)$ & $9(45)$ & $18(30)$ \\
\hline GG & $0(0)$ & $11(55)$ & $0(0)$ & $11(18)$ \\
\hline \multicolumn{5}{|l|}{ IVS3-99A } \\
\hline AA & $12(60)$ & $0(0.0)$ & $5(25)$ & $17(28)$ \\
\hline $\mathrm{AG}$ & $2(10)$ & $9(45)$ & $0(0)$ & $11(18)$ \\
\hline GG & $6(30)$ & $11(55)$ & $15(75)$ & $32(56)$ \\
\hline \multicolumn{5}{|l|}{ Exon3 130G } \\
\hline GG & $20(100)$ & $13(65)$ & $0(0)$ & $33(56)$ \\
\hline $\mathrm{AG}$ & $0(0)$ & $7(35)$ & $10(50)$ & $17(28)$ \\
\hline AA & $0(0)$ & $0(0)$ & $10(50)$ & $10(16)$ \\
\hline \multicolumn{5}{|l|}{ IVS4-299G } \\
\hline GG & $0(0)$ & $0(0)$ & $20(100)$ & $20(33)$ \\
\hline CG & $0(0)$ & $20(100)$ & $0(0)$ & $20(33)$ \\
\hline $\mathrm{CC}$ & $20(100)$ & $0(0)$ & $0(0)$ & $20(33)$ \\
\hline \multicolumn{5}{|l|}{ IVS4-293G } \\
\hline GG & $20(100)$ & $17(85)$ & $9(45)$ & $46(77)$ \\
\hline AG & $0(0)$ & $3(15)$ & $10(50)$ & $13(21)$ \\
\hline AA & $0(0)$ & $0(0)$ & $1(5)$ & $1(2)$ \\
\hline \multicolumn{5}{|l|}{ Exon4 191G } \\
\hline GG & $19(95)$ & $20(100)$ & $20(100)$ & $19(98)$ \\
\hline GA & $1(5)$ & $0(0)$ & $0(0)$ & $1(2)$ \\
\hline $\mathrm{AA}$ & $0(0)$ & $0(0)$ & $0(0)$ & $0(0)$ \\
\hline \multicolumn{5}{|l|}{ IVS4+177T } \\
\hline $\mathrm{TT}$ & $18(90)$ & $20(100)$ & $20(100)$ & $58(97)$ \\
\hline $\mathrm{CT}$ & $2(10)$ & $0(0)$ & $0(0)$ & $2(3)$ \\
\hline $\mathrm{CC}$ & $0(0)$ & $0(0)$ & $0(0)$ & $0(0)$ \\
\hline \multicolumn{5}{|l|}{ IVS4+211C } \\
\hline $\mathrm{CC}$ & $1(5)$ & $19(95)$ & $18(90)$ & $38(63)$ \\
\hline CG & $2(10)$ & $1(5)$ & $2(10)$ & $5(8)$ \\
\hline GG & $17(85)$ & $0(0)$ & $0(0)$ & $17(28)$ \\
\hline \multicolumn{5}{|l|}{ IVS4 +230C } \\
\hline $\mathrm{CC}$ & $10(50)$ & $20(100)$ & $20(100)$ & $50(83)$ \\
\hline $\mathrm{CT}$ & $1(5)$ & $0(0)$ & $0(0)$ & $1(2)$ \\
\hline TT & $9(45)$ & $0(0)$ & $0(0)$ & $9(15)$ \\
\hline
\end{tabular}

IVS5+36 insA, IVS6-27 C, exon6 499A, and exon6 588A(Table 2). Two single nucleotide variants, i.e. exon6 499A and exon6 588A were polymorphic, and we confirmed that these SNPs did not influence $\mathrm{Jk}^{\mathrm{a}}$ or $\mathrm{Jk}^{\mathrm{b}}$ antigen expression because all specimens in our study showed normal expression of Kidd antigens.

\section{Molecular analysis of exons 7 to 11 of $S L C 14 A 1$ gene}

Six single nucleotide variants were found at exons 7 to 11 of the SLC14AI gene, including IVS7-68T, IVS 7+84C, IVS9-46G, IVS9+244G, IVS10-153T, and IVS10-24G(Table 3). The three single nucleotide variants IVS7-68T, IVS9+244G, and IVS10-
Table 2 The single nucleotide variants between exon 5 and 6 of SLC14A1 gene

\begin{tabular}{lcccc}
\multicolumn{1}{c}{ Alleles } & $\mathrm{Jk}(\mathrm{a}+\mathrm{b}-)$ & $\mathrm{Jk}(\mathrm{a}+\mathrm{b}+)$ & $\mathrm{Jk}(\mathrm{a}-\mathrm{b}+)$ & Total \\
\hline Exon8 838G & & & & \\
GG & $20(100)$ & $0(0)$ & $0(0)$ & $20(33)$ \\
GA & $0(0)$ & $20(100)$ & $0(0)$ & $20(33)$ \\
AA & $0(0)$ & $0(0)$ & $20(100)$ & $20(33)$ \\
IVS5-1G & & & & \\
GG & $18(90)$ & $20(100)$ & $20(100)$ & $58(97)$ \\
GA & $2(10)$ & $0(0)$ & $0(0)$ & $2(3)$ \\
AA & $0(0)$ & $0(0)$ & $0(0)$ & $0(0)$ \\
IVS5+36 & & & & \\
insA heterozygous & $9(45)$ & $2(10)$ & $0(0)$ & $11(18)$ \\
IVS6-27C & & & & \\
CC & $20(100)$ & $19(95)$ & $20(100)$ & $59(98)$ \\
CT & $0(0)$ & $1(5)$ & $0(0)$ & $1(2)$ \\
TT & $0(0)$ & $0(0)$ & $0(0)$ & $0(0)$ \\
Exon6 499A & & & & \\
AA & $10(50)$ & $12(60)$ & $20(100)$ & $42(70)$ \\
AG & $6(30)$ & $6(30)$ & $0(0)$ & $12(20)$ \\
GG & $4(20)$ & $2(10)$ & $0(0)$ & $6(10)$ \\
Exon6 588A & & & & \\
AA & $6(30)$ & $3(15)$ & $4(20)$ & $13(21)$ \\
AG & $4(20)$ & $3(15)$ & $6(30)$ & $13(21)$ \\
GG & $10(50)$ & $14(70)$ & $10(50)$ & $34(58)$ \\
\hline
\end{tabular}

153T were polymorphic, and we confirmed that these SNPs do not influence the $\mathrm{Jk}^{\mathrm{a}}$ or $\mathrm{Jk}^{\mathrm{b}}$ antigen expression because all specimens in our study showed normal expression of Kidd antigens. The SNPs IVS7$68 \mathrm{~T}$ and IVS10-153T were absolutely related to nt.838; homozygous IVS7-68TT and IVS10-153GG were associated with homozygous nt.838GG, which expresses the $\mathrm{Jk}(\mathrm{a}+\mathrm{b}-)$ antigen, heterozygous IVS768TC and IVS10-153TG were associated with heterozygous nt.838GA, which expresses the $\mathrm{Jk}(\mathrm{a}+\mathrm{b}+)$ antigen, and homozygous IVS7-68CC and IVS10153TT were associated with homozygous nt.838AA, which expresses $\mathrm{Jk}(\mathrm{a}-\mathrm{b}+)$.

\section{DISCUSSION}

In this study, we investigated the frequencies of mutations in the SLCI4AI gene in Chinese individuals with normal expression of $\mathrm{Jk}^{\mathrm{a}}$ and $\mathrm{Jk}^{\mathrm{b}}$ antigens. Our analysis identified 12 novel alleles in the SLC14AI gene, including IVS3-106A, IVS3-99A, exon3 130G, IVS4-299G, IVS4-293G, IVS4+211C, IVS4+230C, exon6 499A, exon6 588A, IVS7-68T, IVS9+244G, and IVS10-153T, indicating that the gene harbors significant polymorphism. We also showed that IVS4-299, IVS7-68, and IVS10-153 were novel SNPs perfectly associated with exon 8 nt.838.

To the best of our knowledge, the sequence of the SLC14A1 gene in Chinese individuals has not been reported previously. Few studies of Chinese individu- 
Table 3 The single nucleotide variants between exon 7 to 11 of SLC14A1 gene

\begin{tabular}{|c|c|c|c|c|}
\hline & & & & {$[n(\%)$} \\
\hline Alleles & $\mathrm{Jk}(\mathrm{a}+\mathrm{b}-)$ & $\mathrm{Jk}(\mathrm{a}+\mathrm{b}+)$ & $\mathrm{Jk}(\mathrm{a}-\mathrm{b}+)$ & Total \\
\hline Exon 88380 & & & & \\
\hline GG & $20(100)$ & $0(0)$ & $0(0)$ & $20(33)$ \\
\hline GA & $0(0)$ & $20(100)$ & $0(0)$ & $20(33)$ \\
\hline AA & $O(0)$ & $0(0)$ & $20(100)$ & $20(33)$ \\
\hline IVS7-68T & & & & \\
\hline $\mathrm{TT}$ & $20(100)$ & $0(0)$ & $0(0)$ & 20(33) \\
\hline $\mathrm{TC}$ & $0(0)$ & $20(100)$ & $0(0)$ & $20(33)$ \\
\hline $\mathrm{CC}$ & $0(0)$ & $0(0)$ & $20(100)$ & $20(33)$ \\
\hline IVS7 $+84 \mathrm{C}$ & & & & \\
\hline $\mathrm{CC}$ & $1(5)$ & $1(5)$ & $0(0)$ & $2(3)$ \\
\hline $\mathrm{CT}$ & $1(5)$ & $2(10)$ & $1(5)$ & $4(7)$ \\
\hline TT & $18(90)$ & $17(85)$ & $19(95)$ & $54(90)$ \\
\hline IVS9-46G & & & & \\
\hline GG & $20(100)$ & $15(75)$ & $12(60)$ & $47(78)$ \\
\hline GA & $0(0)$ & $5(25)$ & $8(40)$ & $13(22)$ \\
\hline AA & $O(0)$ & $0(0)$ & $0(0)$ & $0(0)$ \\
\hline IVS9+244 G & & & & \\
\hline GG & $0(0)$ & $1(5)$ & $2(10)$ & $3(5)$ \\
\hline GA & $2(10)$ & $5(25)$ & $8(40)$ & $15(25)$ \\
\hline AA & $18(90)$ & $14(70)$ & $10(50)$ & $42(70)$ \\
\hline IVS10-153T & & & & \\
\hline TT & $0(0)$ & $0(0)$ & $20(100)$ & $20(33)$ \\
\hline TG & $O(0)$ & $20(100)$ & $0(0)$ & $20(33)$ \\
\hline GG & $20(100)$ & $0(0)$ & $0(0)$ & $20(33)$ \\
\hline IVS10-24G & & & & \\
\hline GG & $11(55)$ & $11(55)$ & $1(5)$ & $23(38)$ \\
\hline GA & $2(10)$ & $5(25)$ & $9(45)$ & $16(26)$ \\
\hline $\mathrm{AA}$ & $7(35)$ & $4(20)$ & $11(55)$ & $22(36)$ \\
\hline
\end{tabular}

als have reported molecular analyses of subjects with the $\mathrm{Jk}_{\text {null }}$ phenotype. Because normal controls have not been investigated, it is very easy to infer incorrect associations between nucleotide variants in individuals with the $\mathrm{Jk}_{\text {null }}$ phenotype ${ }^{[13]}$. Our study provided data that can serve as a normal control reference and identified 12 novel alleles expressing normal Kidd antigens in the Chinese population. IVS4-299, IVS7-68, and IVS10-153 were novel SNPs expressing $\mathrm{Jk}^{\mathrm{a}}$ and $\mathrm{Jk}^{\mathrm{b}}$ antigens. In our study, we limited the sequencing analysis to exons 1 and 2 in the SLC14Al gene because these two exons encode the urea transporter protein. Whole-gene sequencing may provide additional information on polymorphisms in Chinese individuals.

In summary, our results identified 12 SNPs in the SLC14Al gene in the Chinese population, including SNPs at positions IVS3-106A, IVS3-99A, exon3 130G, IVS4-299G, IVS4-293G, IVS4+211C,
IVS4+230C, exon6 499A, exon6 588A, IVS7-68T, IVS9+244G, and IVS10-153T. Our study also identified three SNPs that make a genotype expressing $\mathrm{Jk}^{\mathrm{a}}$ and $\mathrm{Jk}^{\mathrm{b}}$ antigens in Chinese individuals.

\section{References}

[1] Daniels G. Kidd blood group systems. In: Daniels G, Editor. Human blood groups, 3rd edition. UK: Bristol, 2013: 325-6.

[2] Sands JM, Gargus JJ, Fröhlich O, et al. Urinary concentrating ability in patients with $\mathrm{Jk}(\mathrm{a}-\mathrm{b}-)$ blood type who lack carrier-mediated urea transport. J Am Soc Nephrol, 1992, 2: 1689-96.

[3] Issitt PD, Obarski G, Hartnett PL, et al. Temporary suppression of Kidd system antigen expression accompanied by transient production of anti-Jk3. Transfusion, 1990, 30: $46-50$.

[4] http://intra.blood.org.tw/upload/cd89f368-4d69-48f3bb5d-fd25e83bc8bl.pdf.

[5] Zheng W, Li D, Wang H, et al. Genomic characterization of the $\mathrm{Jk}(\mathrm{a}-\mathrm{b}-)$ phenotype for children in Shenzhen, China. Chinese Journal of Blood Transfusion(in Chinese), 2015, 28(1): 24-5.

[6] Hao L, Du Z, Jin Z. Two cases report of jk(a-b-) and distributions in variety of different races. Acta Anthropologica Sinica(in Chinese), 1991, 10(3): 206-10.

[7] Zhu Z, Sheng W, Cheng H, et al. Rare blood group screening among Chinese blood donors in Shanghai area. Chinese Journal of Blood Transfusion(in Chinese), 2012, 15(4): 232-3.

[8] Hung Y, Xu Y, Wang H, et al. The frequency of Jk(ab-) phenotype in Chengdu blood donors. Chinese Journal of Blood Transfusion(in Chinese), 2011, 24(4): 3.

[9] Marshall CS, Dwyre D, Eckert R, et al. Severe hemolytic reaction due to anti-JK3. Arch Pathol Lab Med, 1999, 123(10): 949-51.

[10] Jator EK. Notorious anti-Jk3 in a pregnant woman. Clin Lab Sci, 2014, 27(2): 78-82.

[11] Guo Z, Wang C, Yan K, et al. The mutation spectrum of the JK-null phenotype in the Chinese population. Transfusion, 2013, 53(3): 545-53.

[12] Xu Z, Lin Y, Chang H. Pedigree investigation of severe hemolytic disease of the newborn caused by rare antiJk3. Asia-Pacific Journal of Blood Types and Genes, 2017, 1: 47-50.

[13] Zhu F, Xu X, Hong X, et al. Research on molecular genetic basis for Jk(a-b-)phenotype. Chinese Journal of Blood Transfusion(in Chinese), 2003, 16(4): 245-7.

(Received 15 November 2017, Revised 03 December 2017, Accepted 07 December 2017) 